\title{
A functional insertion/deletion polymorphism in the IL1A gene is associated with decreased risk of breast cancer
}

\author{
X. Huang ${ }^{1}$, Y. Yang ${ }^{1}$, Z.W. Cui ${ }^{1}$, J. Wang' ${ }^{1}$ and L.B. Gao ${ }^{2}$ \\ 'Department of Laboratory Medicine, the People's Hospital of Leshan, Leshan, \\ Sichuan, China \\ ${ }^{2}$ Laboratory of Molecular and Translational Medicine, \\ West China Institute of Women and Children's Health, \\ Key Laboratory of Obstetric \& Gynecologic and Pediatric Diseases and Birth \\ Defects of Ministry of Education, \\ West China Second University Hospital of Sichuan University, Chengdu, Sichuan, \\ China \\ Corresponding author: X. Huang \\ E-mail: tom_xin@aliyun.com \\ Genet. Mol. Res. 15 (1): gmr.15017486 \\ Received August 20, 2015 \\ Accepted November 9, 2015 \\ Published February 5, 2016 \\ DOI http://dx.doi.org/10.4238/gmr.15017486
}

\begin{abstract}
The insertion/deletion polymorphism (rs3783553 TTCA/-) in the 3' untranslated region of interleukin-1A (IL1A) has been studied intensively and has been shown to affect tumor risk. We studied the frequency of the IL $1 A$ gene polymorphism rs3783553 and evaluated its relationship with breast cancer (BC). A hospital-based case-control study comprising 228 patients with histologically confirmed BC and 241 healthy subjects was conducted. Polymerase chain reaction was used to detect the IL1A rs3783553 polymorphism. The ins/ins (ttca/ttca) genotype was significantly associated with a decreased risk of BC compared with the del/del (-/-) genotype (OR $=0.48,95 \% \mathrm{Cl}=0.27-0.85$ ). Moreover, the ins (ttca) allele distribution between cases and controls was significantly different from the del (-) allele distribution $(\mathrm{OR}=0.74,95 \% \mathrm{Cl}=0.57-0.96)$. Thus, the rs3783553
\end{abstract}


polymorphism is associated with a decreased incidence of breast cancer.

Key words: miRNA; Polymorphism; ILIA; Insertion/deletion; Breast cancer

\section{INTRODUCTION}

Breast cancer $(\mathrm{BC})$ is recognized as the most common malignancy among women in developed western societies (Key et al., 2001; Parkin et al., 2005). Moreover, in many developing countries, such as China, the incidence of BC is increasing by $3-4 \%$ each year, and there is even an increasing prevalence in younger women (Linos et al., 2008). The etiology of tumor genesis in BC is complex and is influenced by many factors, such as age, geographical variation, lifestyle, and especially genetic factors (Dunning et al., 1999). Numerous studies have shown that candidate genes and functional genetic mutations, such as breast cancer 1 , breast cancer 2 , ataxia telangiectasia mutated, and tumor protein p53, are associated with the development of BC (Easton et al., 2007; Stacey et al., 2007; Stacey et al., 2008). Although the molecular and genetic variants related to $\mathrm{BC}$ have been studied intensively, the factors that determine tumor initiation and inheritable BC susceptibility mutations are unclear.

MicroRNAs (miRNAs), which are small non-coding RNAs, act as post-transcriptional regulators of gene expression by binding to the 3' untranslated region (3'UTR) of their target mRNAs (Bartel, 2004). miRNAs are essential for mRNA and protein expression, and there is abundant evidence that single nucleotide polymorphisms located in the 3'UTRs change the strength of miRNA-mRNA binding, resulting in the altered expression of target genes and the risk of cancers (Chin et al., 2008; Jazdzewski et al., 2008; Li et al., 2013; Pan et al., 2014).

Interleukine-1 is a pleiotropic cytokine that plays a critical role in the pathogenesis of inflammatory immune responses and the formation of malignancies (Apte and Voronov, 2008; Kammoun-Krichen et al., 2012). Recently, Gao et al. (2009) found an insertion/deletion polymorphism (rs3783553 TTCA/-) that resides in the 3'UTR of the interleukin-1A gene (IL1A); this polymorphism changes the binding strength of miR-122 and miR-378 to IL1A. The TTCA insertion allele is associated with the elevated transcription of IL-1A in vitro and in vivo. Subsequent studies showed that the rs3783553 ins/ins (TTCA/TTCA) genotype decreases susceptibility to hepatocellular carcinoma (Gao et al., 2009), nasopharyngeal carcinoma (Yang et al., 2011), and gastric cancers (Zeng et al., 2014).

Until date, to our knowledge, no study has evaluated the association between the IL1A rs3783553 polymorphism and $B C$ risk. To elucidate the effects of $I L 1 A$ rs3783553 on the risk of $B C$, we performed a genetic study of the IL1A rs3783553 polymorphism in Chinese women.

\section{MATERIAL AND METHODS}

\section{Study population}

A hospital-based case-control study was designed to evaluate the effect of the IL $1 \mathrm{~A}$ gene rs3783553 polymorphism on the risk of BC. This study comprised 228 patients with histologically confirmed BC and 241 healthy controls. The study population was consecutively recruited from the Han ethnic group and selected from the People's Hospital of Leshan between February 2010 and December 2013. A careful clinical evaluation of these subjects was carried out using medical records that included age, age at menarche, immunohistochemical features, and tumor TNM stage. 
The baseline features of the study subjects are shown in Table 1. The average age was 50.4 years in the $228 \mathrm{BC}$ patients and 48.1 years in the 241 healthy subjects. Patients with recurring $\mathrm{BC}$ or $\mathrm{BC}$ co-occurring with other cancers were excluded. Individuals with historical cancer and inflammatory diseases were also excluded. Unrelated controls were recruited from the healthy volunteers who visited the hospital for physical examination in the same period. The cases and controls were adequately matched in terms of age, age at menarche, and place of residence. This study was approved by the Ethics Committee of the hospital. Written informed consent was obtained from each participant.

\section{Table 1. Characteristics of the study population.}

\begin{tabular}{|c|c|c|}
\hline Variables & BC patients $(N=228)$ & Controls $(N=241)$ \\
\hline Age (years) & $50.4 \pm 9.4$ & $48.1 \pm 11.6$ \\
\hline Age at menarche (years) & $14.1 \pm 1.5$ & $14.1 \pm 1.6$ \\
\hline \multicolumn{3}{|l|}{ Estrogen receptor (\%) } \\
\hline Positive & $143(62.7)$ & \\
\hline Negative & $85(37.3)$ & \\
\hline \multicolumn{3}{|l|}{ Progesterone receptor (\%) } \\
\hline Positive & $124(54.4)$ & \\
\hline Negative & $104(45.6)$ & \\
\hline \multicolumn{3}{|l|}{ TNM grades } \\
\hline \multicolumn{3}{|l|}{ T status (\%) } \\
\hline T1-2 & $178(78.1)$ & \\
\hline T3-4 & $50(21.9)$ & \\
\hline \multicolumn{3}{|l|}{$\mathrm{N}$ status (\%) } \\
\hline No & $97(42.5)$ & \\
\hline N1-3 & $131(57.5)$ & \\
\hline \multicolumn{3}{|l|}{ M status $(\%)$} \\
\hline Mo & $226(99.1)$ & \\
\hline M1 & $2(0.9)$ & \\
\hline
\end{tabular}

$\mathrm{BC}=$ breast cancer.

\section{Genotyping}

Genomic DNA was extracted from peripheral venous blood using a commercial DNA isolation kit (BioTeke Corporation, Beijing, China) according to the manufacturer instructions. A polymerase chain reaction (PCR) assay was used to analyze the IL1A gene rs3783553 polymorphism. Details of the primer sequences and reaction conditions have been described 
previously (Gao et al., 2009; Yang et al., 2011; Zeng et al., 2014). To confirm the accuracy of the genotyping, randomly selected PCR products were sequenced, and the results were verified.

\section{Statistical analysis}

The SPSS software version 19.0 (SPSS Inc., Chicago, IL, USA) was used for the statistical analysis of the data. The Hardy-Weinberg equilibrium (HWE) was accessed using the $c^{2}$ test to compare the observed genotype frequencies among the cases and controls. A two-sided $\mathrm{c}^{2}$ test was used to evaluate the differentials between genotype and allele frequencies of the IL1A rs 3783553 polymorphism both in cases and controls. Odds ratios (ORs) and 95\% confidence intervals (95\% $\mathrm{Cls}$ ) were evaluated to determine the effect of the IL1A rs3783553 polymorphism on BC risk and the different clinical statuses of BC. A P value $<0.05$ was considered statistically significant in the two-sided tests.

\section{RESULTS}

\section{Effect of the IL1A rs3783553 polymorphism on BC risk}

The genotype and allele frequencies of the IL1A rs3783553 polymorphism are displayed in Table 2. The genotype frequencies of $I L-1 A$ rs 3783553 were in agreement with the HWE model in both cases and controls. Among the BC group, the genotype frequencies of the $I L-1 A$ rs 3783553 polymorphism were $39.9,49.6$, and $10.5 \%$ for the del/del (-/-), del/ins (-/ttca), and ins/ins (ttca/ ttca) genotypes, respectively; and for the controls they were $33.6,47.7$, and $18.7 \%$, respectively. The ins/ins (ttca/ttca) genotype was significantly associated with a decreased risk of $\mathrm{BC}$ compared with the del/del $(-/-)$ genotype $(\mathrm{OR}=0.48,95 \% \mathrm{Cl}=0.27-0.85)$. Moreover, the ins (ttca) allele distribution between cases and controls was significantly different from the del (-) allele (OR $=0.74$, $95 \% \mathrm{Cl}=0.57-0.96)$.

Table 2. Genotype and allele frequencies of the IL1A rs 3783553 polymorphism in the breast cancer patients and
controls.
\begin{tabular}{|l|c|c|c|c}
\hline Polymorphism & $\begin{array}{c}\text { Patients } \\
{[N=228(\%)]}\end{array}$ & $\begin{array}{c}\text { Controls } \\
{[N=241(\%)]}\end{array}$ & OR (95\% Cl) & P value \\
\hline del/del (-l-) & $91(39.9)$ & $81(33.6)$ & $1.00($ Ref) & \\
\hline del/ins (-lttca) & $113(49.6)$ & $115(47.7)$ & $0.88(0.59-1.30)$ & 0.51 \\
\hline ins/ins (ttca/ttca) & $24(10.5)$ & $45(18.7)$ & $0.48(0.27-0.85)$ & 0.01 \\
\hline del (-) & $295(64.7)$ & $277(57.5)$ & $1.00($ Ref) & \\
\hline ins (ttca) & $161(35.3)$ & $205(42.5)$ & $0.74(0.57-0.96)$ & 0.02 \\
\hline
\end{tabular}

\section{Effect of the IL1A rs3783553 polymorphism on the clinical features of BC patients}

Further analysis of the effect of the rs 3783553 polymorphism on the clinic features in BC patients is shown in Table 3. No association was found between the rs3783553 polymorphism and the status of estrogen receptor, progesterone receptor, and TNM status of the BC patients. 
Table 3. Association between the IL1A rs3783553 polymorphism and the clinical features of the breast cancer patients.

\begin{tabular}{l|c|c|c|c}
\hline \multirow{2}{*}{ Clinical features } & \multicolumn{2}{|c|}{ Genotype frequency } & \multirow{2}{*}{ OR (95\%Cl) } & \multirow{2}{*}{ P value } \\
\cline { 2 - 3 } & $\mathrm{N}(\%)$ & $\mathrm{N}(\%)$ & & \\
\hline Estrogen receptor & Positive & Negative & & \\
\hline del/del (-/-) & $57(39.9)$ & $34(40.0)$ & $1.00($ Ref) & \\
\hline del/ins (-/ttca) & $73(51.0)$ & $40(47.1)$ & $0.92(0.52-1.63)$ & 0.77 \\
\hline ins/ins (ttca/ttca) & $13(9.1)$ & $11(12.9)$ & $1.42(0.57-3.52)$ & 0.45 \\
\hline del (-) & $187(65.4)$ & $108(63.5)$ & $1.00($ Ref) & \\
\hline ins (ttca) & $99(34.6)$ & $62(36.5)$ & $1.08(0.73-1.61)$ & 0.69 \\
\hline Progesterone receptor & Positive & Negative & & \\
\hline del/del (-/-) & $47(37.9)$ & $44(42.3)$ & $1.00($ Ref) & \\
\hline del/ins (-/ttca) & $67(54.0)$ & $46(44.2)$ & $0.73(0.42-1.28)$ & 0.27 \\
\hline ins/ins (ttca/ttca) & $10(8.1)$ & $14(13.5)$ & $1.50(0.60-3.71)$ & 0.38 \\
\hline del (-) & $161(64.9)$ & $134(64.4)$ & $1.00($ Ref) & \\
\hline ins (ttca) & $87(35.1)$ & $74(35.6)$ & $1.02(0.70-1.50)$ & 0.91 \\
\hline T status & $\mathrm{T} 1-2$ & $\mathrm{~T} 3-4$ & & \\
\hline del/del (-/-) & $71(39.9)$ & $20(40.0)$ & $1.00($ Ref) & \\
\hline del/ins (-/ttca) & $89(50.0)$ & $24(48.0)$ & $0.96(0.49-1.87)$ & 0.90 \\
\hline ins/ins (ttca/ttca) & $18(10.1)$ & $6(12.0)$ & $1.18(0.42-3.38)$ & 0.75 \\
\hline del (-) & $231(64.9)$ & $64(64.0)$ & $1.00($ Ref) & \\
\hline ins (ttca) & $125(35.1)$ & $36(36.0)$ & $1.04(0.65-1.65)$ & 0.87 \\
\hline $\mathrm{N} \mathrm{status}$ & $\mathrm{N} 0$ & $\mathrm{~N} 1-3$ & & \\
\hline del/del (-/-) & $33(34.0)$ & $58(44.3)$ & $1.00($ Ref) & \\
\hline del/ins (-/ttca) & $53(54.6)$ & $60(45.8)$ & $0.64(0.37-1.13)$ & 0.13 \\
\hline ins/ins (ttca/ttca) & $11(11.3)$ & $13(9.9)$ & $0.67(0.27-1.67)$ & 0.39 \\
\hline del (-) & $119(61.3)$ & $176(67.2)$ & $1.00($ Ref) & \\
\hline ins (ttca) & $75(38.7)$ & $86(32.8)$ & $0.78(0.53-1.14)$ & 0.20 \\
\hline & & & & \\
\hline & & & \\
\hline
\end{tabular}

\section{DISCUSSION}

We conducted a hospital-based case-control study and evaluated the potential effects of the IL1A insertion/deletion polymorphism (rs3783553 TTCA/-) on the risk of BC development and progression in Chinese women. Our findings suggested that the distribution of the IL $1 A$ rs3783553 TTCA/- polymorphism was significantly different between the BC patients and controls, which were matched by age, age at menarche, and geographic distinction. The ins/ins (ttca/ttca) genotype possibly protects against the development of BC.

There is abundant evidence that miRNAs, functioning as trans-acting factors, can bind to target genes and play an important role in regulating the development, progression, and metastasis of cancers, including BC (Jazdzewski et al., 2008; Gao et al., 2009; Hollestelle et al., 2011; Zhang et al., 2011). One such miRNA, miR-122, was first recognized as a liver-specific miRNA; it is highly expressed in the liver and is associated with liver-related diseases and hepatocellular carcinoma (HCC). Studies on humans have shown that miR-122 acts as a tumor suppressor in HCC and follicular thyroid carcinoma by decreasing angiogenesis and tumor development (Chang et al., 2008; Reddi et al., 2013). Recently, a novel functional polymorphism (rs3783553 TTCA/-) resident in miR-122 has been discovered, and is reported to affect the transcription of IL $1 \mathrm{~A}$ by changing the binding strength of miR-122 and miR-378 (Gao et al., 2009). The polymorphism has subsequently 
been reported to be related to decreased risk of HCC (Gao et al., 2009), nasopharyngeal carcinoma (Yang et al., 2011), and gastric cancer (Zeng et al., 2014). In this study, we evaluated the potential relationship between the ILIA rs3783553 insertion/deletion polymorphism and the risk of BC, and found that the ILIA rs3783553 ins/ins (ttca/ttca) genotype and the ins (ttca) allele distributions between cases and controls were significantly different. This tumor suppressing effect corroborated previous reports (Gao et al., 2009; Yang et al., 2011; Zeng et al., 2014).

The potential mechanism by which the ILIA rs3783553 polymorphism decreases BC risk may be attributed to the expression of its target gene. IL-1 is a pleiotropic cytokine that is involved in the pathogenesis of inflammatory immune responses and the formation of malignancies (Apte and Voronov, 2008; Kammoun-Krichen et al., 2012). The effect of IL-1 on BC has been extensively studied both in vitro and in vivo. In vitro studies have shown that IL-1 can inhibit malignant cell growth by affecting DNA synthesis (Shen et al., 2002). In human BC, IL-1 is involved in local regulation of tumor growth, angiogenesis, proliferation, and tumor attack (Miller et al., 2000; Pantschenko et al., 2003; Singer et al., 2003). IL-1a may also affect the risk of BC by regulating cell proliferation through a $\mathrm{Ca}^{2+} /$ calmodulin-dependent pathway (Inokuchi et al., 1995), considering that breast calcification is a key risk factor for BC (Tse et al., 2008). However, further more functional studies are needed to elucidate the mechanisms by which the protective effects of the ILIA rs3783553 polymorphism influence BC risk.

This study had some limitations. The study cases were recruited from only one hospital and the control group was recruited from the nearby region, which may not have provided an accurate representation of the general Han population. Furthermore, the sample size was relatively small, which might explain why we did not find any association between the IL1A rs3783553 polymorphism and the clinical features of the BC patients. Therefore, studies with larger sample sizes on subjects from different hospitals and regions might be useful to confirm our findings.

In conclusion, the novel finding of this study is that the $I L 1 \mathrm{~A} \mathrm{rs} 3783553$ polymorphism has a potential protective effect on BC development. It might be useful as a new biomarker and therapeutic target for providing tumorigenesis resistance, although further studies with larger sample sizes are required to confirm our results.

\section{Conflicts of interest}

The authors declare no conflict of interest.

\section{ACKNOWLEDGMENTS}

Research supported by the Natural Science Foundation of the Science and Technology Department of Leshan city (\#13SZD143).

\section{REFERENCES}

Apte RN and Voronov E (2008). Is interleukin-1 a good or bad 'guy' in tumor immunobiology and immunotherapy? Immunol. Rev. 222: 222-241.http://dx.doi.org/10.1111/j.1600-065X.2008.00615.x

Bartel DP (2004). MicroRNAs: genomics, biogenesis, mechanism, and function. Cell 116: 281-297. http://dx.doi.org/10.1016/S0092-8674(04)00045-5

Chang J, Guo JT, Jiang D, Guo H, et al. (2008). Liver-specific microRNA miR-122 enhances the replication of hepatitis C virus in nonhepatic cells. J. Virol. 82: 8215-8223.http://dx.doi.org/10.1128/JVI.02575-07

Chin LJ, Ratner E, Leng S, Zhai R, et al. (2008). A SNP in a let-7 microRNA complementary site in the KRAS 3' untranslated region increases non-small cell lung cancer risk. Cancer Res. 68: 8535-8540. http://dx.doi.org/10.1158/0008-5472.CAN-08-2129 
Dunning AM, Healey CS, Pharoah PD, Teare MD, et al. (1999). A systematic review of genetic polymorphisms and breast cancer risk. Cancer Epidemiol. Biomarkers Prev. 8: 843-854.

Easton DF, Pooley KA, Dunning AM, Pharoah PD, et al.; SEARCH collaborators; kConFab; AOCS Management Group (2007). Genome-wide association study identifies novel breast cancer susceptibility loci. Nature 447: 1087-1093. http://dx.doi.org/10.1038/nature05887

Gao Y, He Y, Ding J, Wu K, et al. (2009). An insertion/deletion polymorphism at miRNA-122-binding site in the interleukin1alpha 3' untranslated region confers risk for hepatocellular carcinoma. Carcinogenesis 30: 2064-2069. http://dx.doi.org/10.1093/carcin/bgp283

Hollestelle A, Pelletier C, Hooning M, Crepin E, et al. (2011). Prevalence of the variant allele rs61764370 T>G in the 3'UTR of KRAS among Dutch BRCA1, BRCA2 and non-BRCA1/BRCA2 breast cancer families. Breast Cancer Res. Treat. 128: 79-84.http://dx.doi.org/10.1007/s10549-010-1080-z

Inokuchi N, Zeki K, Morimoto I, Nakano Y, et al. (1995). Stimulatory effect of interleukin-1 alpha on proliferation through a Ca ${ }^{2+} /$ calmodulin-dependent pathway of a human thyroid carcinoma cell line, NIM 1. Jpn. J. Cancer Res. 86: 670-676. http://dx.doi.org/10.1111/j.1349-7006.1995.tb02451.x

Jazdzewski K, Murray EL, Franssila K, Jarzab B, et al. (2008). Common SNP in pre-miR-146a decreases mature miR expression and predisposes to papillary thyroid carcinoma. Proc. Natl. Acad. Sci. USA 105: 7269-7274. http://dx.doi.org/10.1073/pnas.0802682105

Kammoun-Krichen M, Bougacha-Elleuch N, Mnif M, Bougacha F, et al. (2012). IL-1A a potential factor for discriminating between thyroid carcinoma and atrophic thyroiditis. Eur. Cytokine Netw. 23: 101-106.

Key TJ, Verkasalo PK and Banks E (2001). Epidemiology of breast cancer. Lancet Oncol. 2: 133-140. http://dx.doi.org/10.1016/S1470-2045(00)00254-0

Li ZH, Pan XM, Han BW, Guo XM, et al. (2013). A let-7 binding site polymorphism rs712 in the KRAS 3' UTR is associated with an increased risk of gastric cancer. Tumour Biol. 34: 3159-3163.http://dx.doi.org/10.1007/s13277-013-0885-x

Linos E, Spanos D, Rosner BA, Linos K, et al. (2008). Effects of reproductive and demographic changes on breast cancer incidence in China: a modeling analysis. J. Natl. Cancer Inst. 100: 1352-1360.http://dx.doi.org/10.1093/jnci/djn305

Miller LJ, Kurtzman SH, Anderson K, Wang Y, et al. (2000). Interleukin-1 family expression in human breast cancer: interleukin-1 receptor antagonist. Cancer Invest. 18: 293-302.http://dx.doi.org/10.3109/07357900009012171

Pan XM, Sun RF, Li ZH, Guo XM, et al. (2014). A let-7 KRAS rs712 polymorphism increases colorectal cancer risk. Tumour Biol. 35: 831-835.http://dx.doi.org/10.1007/s13277-013-1114-3

Pantschenko AG, Pushkar I, Anderson KH, Wang Y, et al. (2003). The interleukin-1 family of cytokines and receptors in human breast cancer: implications for tumor progression. Int. J. Oncol. 23: 269-284.

Parkin DM, Bray F, Ferlay J and Pisani P (2005). Global cancer statistics, 2002. CA Cancer J. Clin. 55: 74-108. http://dx.doi.org/10.3322/canjclin.55.2.74

Reddi HV, Driscoll CB, Madde P, Milosevic D, et al. (2013). Redifferentiation and induction of tumor suppressors miR-122 and miR-375 by the PAX8/PPAR $\gamma$ fusion protein inhibits anaplastic thyroid cancer: a novel therapeutic strategy. Cancer Gene Ther. 20: 267-275.http://dx.doi.org/10.1038/cgt.2013.16

Shen WH, Zhou JH, Broussard SR, Freund GG, et al. (2002). Proinflammatory cytokines block growth of breast cancer cells by impairing signals from a growth factor receptor. Cancer Res. 62: 4746-4756.

Singer CF, Kronsteiner N, Hudelist G, Marton E, et al. (2003). Interleukin 1 system and sex steroid receptor expression in human breast cancer: interleukin 1alpha protein secretion is correlated with malignant phenotype. Clin. Cancer Res. 9: 4877-4883.

Stacey SN, Manolescu A, Sulem P, Rafnar T, et al. (2007). Common variants on chromosomes 2q35 and $16 q 12$ confer susceptibility to estrogen receptor-positive breast cancer. Nat. Genet. 39: 865-869.http://dx.doi.org/10.1038/ng2064

Stacey SN, Manolescu A, Sulem P, Thorlacius S, et al. (2008). Common variants on chromosome 5 p12 confer susceptibility to estrogen receptor-positive breast cancer. Nat. Genet. 40: 703-706.http://dx.doi.org/10.1038/ng.131

Tse GM, Tan PH, Cheung HS, Chu WC, et al. (2008). Intermediate to highly suspicious calcification in breast lesions: a radiopathologic correlation. Breast Cancer Res. Treat. 110: 1-7.http://dx.doi.org/10.1007/s10549-007-9695-4

Yang ZH, Dai Q, Zhong L, Zhang X, et al. (2011). Association of IL-1 polymorphisms and IL-1 serum levels with susceptibility to nasopharyngeal carcinoma. Mol. Carcinog. 50: 208-214.http://dx.doi.org/10.1002/mc.20706

Zeng XF, Li J and Li SB (2014). A functional polymorphism in IL-1A gene is associated with a reduced risk of gastric cancer. Tumour Biol. 35: 265-268.http://dx.doi.org/10.1007/s13277-013-1034-2

Zhang L, Liu Y, Song F, Zheng H, et al. (2011). Functional SNP in the microRNA-367 binding site in the 3'UTR of the calcium channel ryanodine receptor gene 3 (RYR3) affects breast cancer risk and calcification. Proc. Natl. Acad. Sci. USA 108: 13653-13658.http://dx.doi.org/10.1073/pnas.1103360108 